\title{
New Agents in the Treatment of Chronic Myelogenous Leukemia
}

Javier Pinilla-Ibarz, MD, PhD, ${ }^{a}$ and Alfonso Quintás-Cardama, MD, ${ }^{\mathrm{b}}$ Tampa, Florida, and Houston, Texas

\author{
Key Words \\ Chronic myeloid leukemia, imatinib resistance, imatinib intoler- \\ ant, second generation tyrosine kinase inhibitors
}

\begin{abstract}
The discovery of molecularly targeted agents that selectively inhibit bcr-abl tyrosine kinase activity, such as imatinib, has revolutionized the treatment and natural history of chronic myelogenous leukemia (CML). Treatment of chronic-phase CML with imatinib showed complete cytogenetic response rates of more than $40 \%$ in patients after failure of interferon- $\alpha$, and more than $80 \%$ in patients with newly diagnosed CML. Patients with CML can now expect excellent long-term survival, often without major side effects. In most patients, however, residual leukemic burden remains detectable using a sensitive reverse transcription-polymerase chain reaction method. In addition, many patients undergoing imatinib therapy will either not respond or lose their response over time because of resistance or intolerance. The introduction of secondgeneration tyrosine kinase inhibitors (TKIs) re-establishes response in approximately half of these patients. Several agents are being developed for treating patients who experience suboptimal response to second-generation TKIs and for those who develop resistance caused by the emergence of highly resistant BCR-ABL1 mutations. This article provides an overview of novel targeted agents available for CML. (JNCCN 2009;7:1028-1037)
\end{abstract}

Imatinib is a selective inhibitor at the ATP binding site of the BCR-ABL protein, blocking downstream signaling pathways involved in the proliferation of

From the aDivision of Malignant Hematology, H. Lee Moffitt Cancer Center \& Research Institute, Tampa, Florida, and bepartment of Leukemia, The University of Texas M. D. Anderson Cancer Center Houston, Texas.

Submitted July 11, 2009; accepted for publication August 27, 2009. Dr. Pinilla-lbarz received research support from Novartis, Bristol Myers Squibb, Innovive, and Exelixis. He also serves on the

Novartis speaker's bureau. Dr. Quintás-Cardama has no significant relationships to disclose.

Correspondence: Javier Pinilla-lbarz, MD, PhD, Malignant Hematology Division, H. Lee Moffitt Cancer Center \& Research Institute, 12902 Magnolia Drive, MRC-3056H, Tampa, FL 33612.

E-mail: Javier.Pinilla@moffitt.org the malignant clone. Several other tyrosine kinases, including c-KIT and platelet-derived growth factor receptor (PDGFR), are also inhibited by imatinib. This drug has been shown to induce complete hematologic and cytogenetic remissions in a high percentage of patients with chronic-phase chronic myelogenous leukemia (CML). ${ }^{1-5}$ These high response rates and duration translate into a remarkable overall survival; among the highest in the history of CML. However, recent studies, including an intention-to-treat analysis in a more "reallife" setting, showed that after 5 years of treatment, 37\% to $49 \%$ of patients require further therapy after exhibiting resistance or intolerance. ${ }^{6-8}$

Primary resistance to imatinib is defined as experiencing 1) no complete hematologic response (CHR) at 3 months, 2) any cytogenetic response at 6 months, $3)$ a major cytogenetic response (MCyR) at 12 months, or 4) no complete cytogenetic response (CCyR) at 18 months. ${ }^{9}$ According to data from the International Randomized Interferon versus STI571 (IRIS) trial, these milestones are not achieved in 5\%,22\%, 23\%, and $24 \%$ of patients, respectively. ${ }^{2}$ A subset of patients exhibit secondary resistance; that is, the loss of a previously achieved response. ${ }^{10}$

After 5 years of follow-up in the IRIS trial, the estimated relapse rate was $17 \%$, with a $7 \%$ progression to a more advanced phase. Various mechanisms are likely to contribute to imatinib resistance, including increased efflux or influx of the drug from the cancer cell, mediated by membrane transporters, such as the multidrugresistance gene 1 protein (MDR-1) or human organic cation transporter protein (hOCT-1);11,12 increased expression of BCR-ABL kinase through gene amplification; ${ }^{13,14}$ increased imatinib binding by plasma proteins; and clonal evolution. ${ }^{10,15}$

One of the best established causes of imatinib resistance is the acquisition of point mutations within the 
ABL kinase domain, which are detected in $22 \%$ to $55 \%$ of patients. ${ }^{10,13}$ These point mutations result in destabilization of the inactive conformation of the enzyme that is required for the binding of imatinib. ${ }^{14,16}$ More than 40 different mutations have been described, ${ }^{17}$ most of them mapping at contact residues (e.g., T315I, F317L) or the ATP binding loop (Ploop). ${ }^{18}$ P-loop mutations can confer high levels of resistance to imatinib and have been associated with poor prognosis. ${ }^{19}$ The T315I mutation renders BCRABL cells insensitive to imatinib and other clinically available tyrosine kinase inhibitors (TKIs) but does not always predict the clinical course..$^{20,21}$ Other described mutations can be overcome by higher levels of imatinib. ${ }^{22}$ Overexpression of SRC family kinases, such as HCK, LYN, and, more recently, FYN, has also been implicated as a BCR-ABL-independent imatinib-resistant mechanism. ${ }^{23-26}$

The response to imatinib therapy should be carefully monitored according to defined milestones. The 2009 NCCN Clinical Practice Guidelines in Oncology: Chronic Myelogenous Leukemia (in this issue; to view the most recent version of these guidelines, visit the NCCN Web site at www.nccn.org) and European LeukemiaNet recommend time-based milestone responses that should be achieved for continuing the same imatinib dosing schedule. Emerging evidence suggests that earlier milestones than those proposed by NCCN are warning signs in patients unlikely to obtain long-term benefits from imatinib. Inability to achieve a CCyR at 12 months of imatinib treatment has been associated with a higher risk for disease progression. ${ }^{2}$ Another recent retrospective study showed that inability to achieve a MCyR by 6 months predicted decreased overall survival. ${ }^{27,28}$ A recent publication using mainly high-dose imatinib showed that patients unable to achieve a 1-log reduction in BCR-ABL transcripts at 3 months, or more than a 2-log at 6 months, are unlikely to obtain a substantial response and are at high risk for disease progression. ${ }^{29}$

\section{Treatment Options for Patients Resistant to Imatinib Therapy}

Loss of response or disease progression should prompt a change in treatment. ${ }^{30}$ Two major treatment options are clinically available for managing patients resistant to imatinib therapy: high-dose imatinib and second-generation TKIs (e.g., nilotinib, dasatinib). The phase III Tyrosine Kinase Inhibitor Optimization and Selectivity (TOPS) study reported that high-dose imatinib was not superior to standarddose in terms of major molecular response (MMR) rates at 12 months among patients with early chronic-phase CML. However, longer follow-up may be required to show a potential benefit of high-dose imatinib therapy. ${ }^{31}$

\section{Second-Generation TKIs}

Nilotinib: Nilotinib (Tasigna, AMN-107, Novartis International AG, Basel, Switzerland), is an aminopyrimidine-based imatinib analog that disrupts the ATP-phosphate-binding pocket of the ABL tyrosine kinase but also has important activity against c-KIT, PDGFR, and ephrin receptor kinase. Nilotinib is 30-fold more potent than imatinib against unmutated BCR-ABL in vitro ${ }^{32}$ and effectively inhibits 32 of 33 imatinib-resistant BCR-ABL mutations, ${ }^{33-35}$ but not the T315I mutant. ${ }^{36}$ Certain P-loop mutations pose intermediate/high levels of resistance to nilotinib. ${ }^{35-37}$

In October 2007, the FDA approved nilotinib at a dose of $400 \mathrm{mg}$ twice a day for treating patients with imatinib-resistant or -intolerant CML in chronic or accelerated phase.

The pivotal phase II study involved 321 patients with CML in chronic phase (71\% imatinib-resistant, $29 \%$ imatinib-intolerant; Table 1). ${ }^{38}$ Most patients were heavily pretreated; $72 \%$ received more than $600 \mathrm{mg}$ daily of imatinib before study entry. Furthermore, patients intolerant to imatinib could not have experienced prior $\mathrm{MCyR}$ while on imatinib. After 24 months of follow-up, the overall MCyR rate was $58 \%$ and the CCyR was $42 \%$. Responses were durable, with $84 \%$ of patients maintaining the MCyR at 18 months. The time-to-progression analysis showed that $64 \%$ of patients had not experienced progression at 18 months, with an overall survival rate of $91 \%$.

The most frequently reported grade 3 to 4 biochemical laboratory abnormalities were transient and clinically asymptomatic, including elevated lipase $(16 \%)$, hypophosphatemia (15\%), hyperglycemia (12\%), and elevated total bilirubin (7\%). Grade 3 to 4 nonhematologic adverse events were infrequent, with rash, headache, and diarrhea occurring in only $2 \%$ of patients. The most common grade 3 to 4 hematologic laboratory abnormalities included neutropenia (30\%), thrombocytopenia (28\%), and 
Pinilla-Ibarz and Quintás-Cardama

\begin{tabular}{|c|c|c|c|c|c|c|c|c|c|c|c|}
\hline \multirow[b]{3}{*}{ Response } & \multicolumn{11}{|c|}{$\%$ Response } \\
\hline & \multicolumn{4}{|c|}{ Dasatinib } & \multicolumn{4}{|c|}{ Nilotinib } & \multicolumn{3}{|c|}{ Bosutinib } \\
\hline & $\begin{array}{l}\mathrm{CP} \\
\mathrm{N}=387\end{array}$ & $\begin{array}{l}\text { AP } \\
N=174\end{array}$ & $\begin{array}{l}\text { MyBP } \\
N=109\end{array}$ & $\begin{array}{l}\text { LyBP } \\
\mathrm{N}=48\end{array}$ & $\begin{array}{l}\mathrm{CP} \\
\mathrm{N}=321\end{array}$ & $\begin{array}{l}A P \\
N=137\end{array}$ & $\begin{array}{l}\text { MyBP } \\
\mathrm{N}=105\end{array}$ & $\begin{array}{l}\text { LyBP } \\
N=31\end{array}$ & $\begin{array}{l}\mathrm{CP} \\
\mathrm{N}=146\end{array}$ & $\begin{array}{l}\text { AP } \\
N=51\end{array}$ & $\begin{array}{l}\mathrm{BP}^{84} \\
\mathrm{~N}=38\end{array}$ \\
\hline \% Resistant & 74 & 93 & 91 & 88 & 70 & 80 & 82 & 82 & 69 & $N R^{*}$ & $N R^{*}$ \\
\hline Hematologic & & 79 & 50 & 40 & 94 & 56 & 22 & 19 & 85 & 54 & 36 \\
\hline - $\mathrm{CHR}$ & 91 & 45 & 27 & 29 & 76 & 31 & 11 & 13 & 81 & 54 & 36 \\
\hline • NEL & - & 19 & 7 & 6 & - & 12 & 1 & 0 & - & 0 & 0 \\
\hline Cytogenetic & $N R$ & 44 & 36 & 52 & NR & $N R$ & NR & NR & & NR & $N R$ \\
\hline - Complete & 49 & 32 & 26 & 46 & 44 & 20 & 29 & 32 & 34 & 27 & 35 \\
\hline - Partial & 11 & 7 & 7 & 6 & 15 & 12 & 10 & 16 & 13 & 20 & 18 \\
\hline $\begin{array}{l}\% \text { Survival at } \\
\text { (x) months }\end{array}$ & $96(15)$ & $82(12)$ & $50(12)$ & $50(5)$ & $88(24)$ & $67(24)$ & $42(12)$ & $42(12)$ & $98(12)$ & 60 (12) & $50(10)$ \\
\hline
\end{tabular}

Abbreviations: $\mathrm{AP}$, advanced phase; $\mathrm{BP}$, blast phase; $\mathrm{CHR}$, complete hematologic response; $\mathrm{CP}$, chronic phase; LyBP, lymphoid blast phase; MyBP, myeloid blast phase; NEL, no evidence of leukemia; NR, not reported.

* $48 \%$ had previously undergone dasatinib or nilotinib therapy in addition to imatinib.

anemia $(10 \%)$. QTcF prolongation greater than 500 milliseconds was rare, occurring in only 3 patients $(<1 \%)$. Nilotinib was active in patients harboring different mutations, except T315I, but had limited activity in patients with $\mathrm{Y} 253 \mathrm{H}, \mathrm{E} 255 \mathrm{~K} / \mathrm{V}$, and F359C/V.

A phase II trial to characterize the efficacy and safety of nilotinib, $400 \mathrm{mg}$ twice daily, in patients with imatinib-resistant advanced-phase CML was recently updated. ${ }^{39,40}$ This analysis included 138 patients, with 80\% imatinib-resistant and 20\% imatinib-intolerant. Of 134 patients with at least 6 months of follow-up, $56 \%$ experienced a hematologic response, including 30\% who had a CHR. MCyR and CCyR occurred in $32 \%$ and $19 \%$ of patients, respectively. Cytogenetic responses were durable, with $69 \%$ of patients maintaining MCyR at 18 months. The median time to progression was 16 months, and the estimated overall survival at 1 year was $82 \%$. The most frequently reported grade 3 to 4 laboratory abnormalities were thrombocytopenia (40\%), neutropenia (40\%), anemia (25\%), elevated serum lipase (17\%), and hypophosphatemia (12\%). Grade 3 to 4 nonhematologic adverse events were uncommon $(<1 \%)$ and included rash, nausea, fatigue, and diarrhea.

Data from a phase II trial evaluating nilotinib in patients with previously untreated chronic-phase CML were recently reported..$^{41}$ Forty-nine patients were treated for a median of 13 months at a median dose of $400 \mathrm{mg}$ twice daily. Of 48 patients, 46 (96\%) experienced a CCyR, at a rate of 3, 6, and 12 months comparing favorably with imatinib. MMR was observed in $45 \%$ of patients at 6 months and $52 \%$ at 12 months. The 24-month event-free survival rate was $95 \%$. The actual median dose was $800 \mathrm{mg}$ daily. Toxicity was manageable, with myelosuppression being the main adverse event. A multicenter phase III trial is underway comparing nilotinib with standard-dose imatinib $(400 \mathrm{mg} / \mathrm{d})$ for treating patients with newly diagnosed chronic-phase CML.

Dual Src Family/Abl TKIs: Dasatinib: Dasatinib (Sprycel, Bristol-Myers Squibb, New York, New York) is an orally available multi-targeted inhibitor of BCR-ABL, Src family, c-Kit, EPHA2, and PDGFR $\beta$, among others. ${ }^{42-45}$ Dasatinib is approximately 325-fold more potent than imatinib against BCR-ABL. Unlike imatinib, dasatinib can bind to both the active and inactive conformations of the ABL kinase domain and has activity against many imatinib-resistant BCR-ABL mutations, including those within the P-loop, the activation loop, and other sites in the $\mathrm{COOH}$-terminal loop, except for T315I. ${ }^{36,46,47}$

Based on its activity after imatinib failure in patients with CML (Table 1), the FDA approved dasatinib in 2006 for treating CML resistant to prior therapy. The START-C trial evaluated 387 patients (288 imatinib-resistant and 99 imatinib-intolerant) 
with chronic-phase CML. ${ }^{48-50}$ The starting dose was dasatinib, $70 \mathrm{mg}$ twice daily, and the primary end point was $\mathrm{MCyR}$ rate. Best response to prior imatinib therapy was $\mathrm{CHR}$ in $82 \%, \mathrm{MCyR}$ in $37 \%$, and $\mathrm{CCyR}$ in $19 \%$ of patients.

After a minimum follow-up of 24 months, CHR was noted in $91 \%$ of patients (95\% CI, 88\%-94\%), MCyR in 62\% (95\% CI, 57\%-67\%), CCyR in 53\%, and MMR in $47 \%$. MCyR occurred in $55 \%$ of patients resistant to imatinib, and in $63 \%$ of those with baseline BCR-ABL mutations, except those carrying T315I. At 24 months, progression-free survival was $80 \%$ (75\% in imatinib-resistant and $94 \%$ in -intolerant patients) and overall survival was $94 \%$ (92\% in imatinib-resistant and 100\% in -intolerant patients). The main grade 3 to 4 toxicities included thrombocytopenia (49\%), neutropenia (50\%), pleural effusion $(9 \% ; 35 \%$ all grades), dyspnea $(6 \%)$, and bleeding (4\%).

Another phase II study, the START-R trial, randomized (2:1) patients with imatinib-resistant chronic-phase CML to receive dasatinib, $70 \mathrm{mg}$ twice daily $(\mathrm{n}=101)$, or imatinib, $800 \mathrm{mg}$ daily $(\mathrm{n}=49) .{ }^{51}$ At a minimum follow-up of 2 years, dasatinib showed higher rates of CHR (93\% vs. $82 \%$; $P=.034)$, MCyR (53\% vs. $33 \% ; P=.017)$, and CCyR (44\% vs. $18 \%$; $P=.0025)$. At 18 months, MCyR was maintained in $90 \%$ of patients on the dasatinib arm and $74 \%$ on the high-dose imatinib arm. MMR rate was also higher in patients treated with dasatinib than with high-dose imatinib (29\% vs. $12 \% ; P=.028)$. The estimated progression-free survival also favored dasatinib. Grade 3 to 4 toxicities included thrombocytopenia (57\%), neutropenia (63\%), and pleural effusion (5\%).

The efficacy of dasatinib in advanced-and blastphase CML was also shown in the phase II START-A and -B trials, respectively. In the START-A trial, 174 patients with imatinib-resistant or -intolerant advanced-phase CML were treated with dasatinib. ${ }^{52,53}$ At a follow-up of 2 years, the reported CHR, MCyR, and CCyR rates were $50 \%, 45 \%$, and $33 \%$, respectively. The 2-year progression-free survival rate was $46 \%$, with a median progression-free survival of 19.5 months. The 2 -year overall survival rate was $72 \%$; median overall survival had not been reached. Dasatinib was generally well tolerated; the most frequent nonhematologic severe treatment-related adverse event was diarrhea (52\%; grade 3 to 4 in $8 \%$ ).
Cytopenias were common, including grade 3 to 4 neutropenia (76\%) and thrombocytopenia (82\%). Pleural effusion occurred in $27 \%$ of patients (grade $3-4$ in $5 \%$ ).

The START-B trial evaluated 157 patients with imatinib-resistant or -intolerant CML in blast phase. ${ }^{54}$ This trial reported a CHR rate of $26 \%$ in patients with myeloid blast phase and $29 \%$ in those with lymphoid blast phase, and an MCyR rate of $34 \%$ and $52 \%$, respectively. The CCyR rate was $27 \%$ and $46 \%$, respectively. Overall survival was higher in those with myeloid blast crisis than lymphoid blast crisis, with a median overall survival of 11.8 versus 5.3 months.

The currently approved dose for chronic-phase CML is $100 \mathrm{mg}$ daily based on results from the phase III dose optimization trial showing that this dose schedule was not inferior to twice-daily schedules and that it had an improved toxicity profile, particularly regarding rates of grade 3 to 4 neutropenia, thrombocytopenia, and pleural effusion..$^{55}$ Dasatinib received full FDA approval in May 2009. The currently approved starting dosage for patients with advanced-phase CML, myeloid blast phase, and Philadelphia chromosome-positive acute lymphoblastic leukemia $(\mathrm{Ph}+\mathrm{ALL})$ resistant or intolerant to prior therapy is $140 \mathrm{mg}$ daily.

Given the activity of dasatinib in patients for whom therapy with imatinib had failed, a phase II trial is exploring this TKI in treatment-naïve patients with chronic-phase CML. Results evaluating 50 patients showed CCR rates of $78 \%, 93 \%$, and $97 \%$ at 3,6 , and 12 months, respectively. ${ }^{56}$ A multicenter phase III trial comparing dasatinib with standard-dose imatinib (400 mg) for treating patients with newly diagnosed chronic-phase CML is underway.

Bosutinib: Bosutinib is an orally available potent dual $\mathrm{Src} / \mathrm{Abl}$ kinase inhibitor. It has been shown to be up to 200-fold more potent than imatinib as an inhibitor of Bcr-Abl phosphorylation, but it has minimal inhibitory activity against PDGRF or c-Kit. In addition, bosutinib has shown activity against most imatinib-resistant mutants of Bcr-Abl, except for T315I.

Results were recently reported from a phase II study involving 283 patients with chronic-phase CML for whom treatment with imatinib or other second-generation TKIs failed ${ }^{57}$ (Table 1). In patients for whom only treatment with imatinib failed, 
Pinilla-Ibarz and Quintás-Cardama

bosutinib rendered a CHR rate of $79 \%$ and a MCyR rate of $40 \%$ (29\% CCyR). The most common adverse events were gastrointestinal (mostly diarrhea), but these were usually grade 1 to 2 , manageable, and diminishing in frequency and severity after the first 3 to 4 weeks of treatment.

A separate phase II trial evaluating patients with advanced- or blast-phase CML for whom prior therapy with imatinib had failed ${ }^{58}$ showed a $73 \% \mathrm{MCyR}$ rate and a 36\% MMR rate. These data, although preliminary, indicate that bosutinib has activity in advanced-phase CML after imatinib failure. In addition, it seems to have a safer toxicity profile than other second-generation TKIs, perhaps because of its lack of activity against c-kit and PDGFR. An ongoing phase III trial is evaluating bosutinib versus imatinib. INNO-406: INNO-406 is an orally available, dual $\mathrm{Abl} /$ Lyn kinase inhibitor that is 55 times more potent than imatinib in Bcr-Abl-expressing cell lines. ${ }^{59}$ It inhibits a wide range of $\mathrm{Bcr}-\mathrm{Abl}$ kinase domain mutants, including F317L/V, but excluding T315I. INNO-406 has also been shown to cross the bloodbrain barrier, making it a potential treatment option in patients with central nervous system disease. ${ }^{60}$ Results were recently reported from a phase I study involving patients with imatinib-resistant or -intolerant CML in chronic phase $(\mathrm{n}=21)$, advanced phase $(n=9)$, blast phase $(n=7)$, or Ph+ALL $(n=$ 9). ${ }^{61,62}$ Nineteen patients remain in the study. CCyR occurred in 3 patients for whom treatment with imatinib had previously failed. Drug-related grade 3 to 4 adverse events included reversible elevations of transaminases and bilirubin, thrombocytopenia, and acute renal failure. Further development of this TKI in CML is uncertain.

Compounds With Activity Against T315I: None of the TKIs described have activity against the T315I mutation, which accounts for $10 \%$ to $20 \%$ of the BCR-ABL1 mutants detected after failure of TKI therapy. A series of compounds have shown important preclinical activity against BCR-ABL1 T315I kinase; some have entered clinical trials for evaluation in patients for whom treatment with 2 or more TKIs failed or who are carrying the T315I mutation. Many of these agents are multikinase inhibitors with activity against, among others, BCR-ABL1 and Aurora kinases. Aurora kinases are key regulators of cellular mitosis and have been shown to be overexpressed in multiple cancers. ${ }^{63}$ MK-0457 (formerly
VX-680) is a potent Aurora kinase and JAK2 inhibitor that showed activity in patients with the T315I BCR-ABL mutation. ${ }^{64}$ Cardiac toxicity precluded further development of this compound for this indication. However, other Aurora kinase inhibitors have shown promising preliminary clinical results (Table 2).

XL228: XL228 is a multikinase inhibitor with potent inhibitory activity against Aurora A ( $\mathrm{IC}_{50}$, approximately $3 \mathrm{nM}), \mathrm{ABL} 1\left(K_{\mathrm{i}}, 5 \mathrm{nM}\right)$, and BCRABL1 T315I $\left(K_{i}, 1.4 \mathrm{nM}\right)$, and other kinases such as SRC and insulin-like growth factor type $1 .{ }^{65} \mathrm{~A}$ phase I dose escalation study was recently updated in subjects with CML or Ph+ ALL for whom prior therapy with imatinib and dasatinib failed. ${ }^{66}$ Evidence of clinical activity was observed in 17 patients (7 with T315I) treated at doses of $3.6 \mathrm{mg} / \mathrm{kg}$ or greater, including stable or decreasing white blood cell or platelet count within 2 months. Dose escalation is ongoing.

PHA-739358: PHA-739358, a pan-Aurora kinase inhibitor, is currently being evaluated in a multicenter phase II trial. ${ }^{67}$ In vitro experiments in cellular assays have shown that the antiproliferative activity of PHA-739358 is partially independent of BCR-ABL1 kinase, because the sensitivity to PHA739358 is not dependent on BCR-ABL1 mutational status given that similar inhibitory activities were elicited in all imatinib-resistant mutants, including T315I. Preliminary results, reported on 7 patients, showed that 2 of 6 with the T315I mutation experienced response to therapy at a dosage of $330 \mathrm{mg} / \mathrm{m}^{2}$. Both achieved CHR, including 1 in advanced phase who experienced an ongoing CCyR after more than 6 months of therapy and a CMR. The second patient, who had chronic-phase CML, achieved a minor CyR. None of the 5 patients in blast crisis experienced a clinical response.

Switch Pocket Inhibitors: An alternate approach to tackling the T315I mutation is to develop compounds that target BCR-ABL1 kinase by binding to regulatory sites distant from the catalytic domain of the enzyme. A novel chemical class of TKIs circumvents the gatekeeper T315I mutation by binding to several pockets involved in the "switch" mechanism the ABL kinase uses to control its transition from the inactive to the active state. DCC-2036, the first agent of this class, inhibits purified ABL kinase that is either unphosphorylated (switch-off) or phosphor- 
New Agents for CML Treatment

\begin{tabular}{|c|c|c|c|c|c|c|}
\hline Drug & Chemical Class & $\begin{array}{l}\text { Aurora } \\
\text { Selectivity }\end{array}$ & $\begin{array}{l}\text { Other } \\
\text { Targets }\end{array}$ & Route & Stage & Comments \\
\hline MK-0457 & $\begin{array}{l}\text { Pyrazolo- } \\
\text { quinazoline }\end{array}$ & $\begin{array}{l}\text { Aurora A, } \\
B \text {, and C }\end{array}$ & $\begin{array}{l}\text { ABL1, FLT3, } \\
\text { JAK2 }\end{array}$ & IV & Phase II & $\begin{array}{l}\text { Development stopped } \\
\text { due to cardiac toxicity }\end{array}$ \\
\hline XL228 & Not available & Aurora A & $\begin{array}{l}\text { ABL1, IGF1R, } \\
\text { SRC }\end{array}$ & IV & Phase I & $\begin{array}{l}\text { Tested in CML and } \mathrm{Ph}+ \\
\mathrm{ALL} \text { after failure of } \\
\text { imatinib or dasatinib }\end{array}$ \\
\hline PHA-739358 & $\begin{array}{l}\text { Pyrrolo- } \\
\text { pyrazole }\end{array}$ & $\begin{array}{l}\text { Aurora A, } \\
B \text {, and C }\end{array}$ & $\begin{array}{l}\text { ABL1, FGFR1, } \\
\text { RET, TRK-A }\end{array}$ & IV & Phase II & $\begin{array}{l}\text { Tested in CML after } \\
\text { failure of imatinib } \\
\text { or other anti-ABL1 } \\
\text { treatments }\end{array}$ \\
\hline AT-9283 & Not available & $\begin{array}{l}\text { Aurora A, } \\
B \text {, and C }\end{array}$ & $\begin{array}{l}\text { ABL1, FLT3, } \\
\text { JAK2, JAK3 }\end{array}$ & IV/Oral & Phase I/II & $\begin{array}{l}\text { Being tested in } \\
\text { patients with } \\
\text { refractory hematologic } \\
\text { malignancies including } \\
\text { CML }\end{array}$ \\
\hline KW-2449 & Not available & Aurora A & $\begin{array}{l}\text { ABL1, FLT3, } \\
\text { FGFR1, } \\
\text { VEGFR }\end{array}$ & Oral & Phase I & $\begin{array}{l}\text { Undergoing clinical } \\
\text { testing in } \mathrm{CML} \text {, acute } \\
\text { leukemia, and high-risk } \\
\text { MDS }\end{array}$ \\
\hline
\end{tabular}

Abbreviations: ALL, acute lymphoblastic leukemia; CML, chronic myelogenous leukemia; FGFR1, fibroblast growth factor receptor-1; FLT3, FMS-like tyrosine kinase 3; IGF1R, insulin-like growth factor type-1 receptor; IV, intravenous; MDS, myelodysplastic syndrome; $\mathrm{Ph}+$, Philadelphia chromosome positive.

ylated (switch-on) at Tyr393 with $\mathrm{IC}_{50}$ of 0.8 to 4.0 nM. A phase I study with this compound was just launched for patients carrying T315I or for whom treatment with 2 or more TKIs failed. ${ }^{68}$

Non-TKI Approaches for the Management of T315I: Omacetaxine mepesuccinate is a semisynthetic form of homoharringtonine, a plant alkaloid derived from an evergreen tree of the genus Cephalotaxus. Omacetaxine inhibits protein synthesis and induces apoptosis and, in combination with imatinib, is synergistic or additive in CML cell lines. An international phase II/III clinical study (CML-202) is evaluating the activity of SC omacetaxine in patients with BCR-ABL1 T315I-positive CML. So far, 66 patients (40 in chronic, 16 in advanced, and 10 in blast phase) have received omacetaxine. ${ }^{69} \mathrm{CHR}$ rates for patients in chronic, advanced, or blast phase were $85 \%, 31 \%$, and $20 \%$, respectively. Among patients in chronic phase, the MCyR rate was 33\% for those who entered the study with CHR and 7\% for those with no CHR at study entry. One patient with advanced-phase CML experienced a CCyR, but no patient with blast phase experienced a cytogenetic response. The median duration of $\mathrm{CHR}$ in chronic phase was 9 months. The BCR-ABL1 T315I clone became undetectable in 19 (48\%) of 40 evaluable patients. Among patients in chronic phase, the most frequent grade 3 to 4 toxicities were thrombocytopenia $(70 \%)$, anemia (55\%), and neutropenia (43\%). If maintained, the results of this trial may lead to the approval of omacetaxine for treating patients with BCR-ABL1 T315I-positive CML.

Another approach to the management of patients with BCR-ABL1 T315I-positive CML is the use of epigenetic modifiers. Histone deacetylases (HDAC) catalyze the deacetylation of lysine residues at the amino termini of core nucleosomal histones. Inhibition of HDACs with HDAC inhibitors cause hyperacetylation of histones, leading to transcriptional upregulation of cyclin-dependent kinase inhibitor, p21, cell-cycle arrest, and apoptosis in tumor cells. ${ }^{70} \mathrm{HDAC}$ inhibitor treatment results in depletion of BCR-ABL1 protein and sensitization to imatinib-induced apoptosis. ${ }^{71}$ In preclinical studies of cells obtained from patients with CML expressing the T315I mutation, treatment with the HDAC inhibitor LBH589 in combination with nilotinib resulted in synergistic reduction of STAT5 and ERK1/2 phosphorylation, and enhanced apoptosis. ${ }^{72}$ Similar effects were observed when dasatinib was 
Pinilla-Ibarz and Quintás-Cardama

combined with the HDAC inhibitor suberoylanilide hydroxamic acid (SAHA). ${ }^{73}$ Ongoing clinical trials are evaluating the activity of HDAC inhibitors in patients with CML in all phases after TKI failure and in those carrying BCR-ABL1 T315I.

Bcr-Abl activates PI-3 kinase through a direct association with its $85 \mathrm{kd}$ regulatory subunit; signaling by way of the PI-3 kinase is essential for the growth of CML progenitors. The mammalian target of rapamycin (mTOR) is a serine-threonine kinase downstream of PI-3 kinase that is activated on phosphorylation by Akt. ${ }^{74}$ Recently, RAD001 (Everolimus, Novartis International AG, Basel, Switzerland), a derivative of the mTOR rapamycin, has been shown to inhibit the growth of $\mathrm{Ba} / \mathrm{F} 3-\mathrm{Bcr}-\mathrm{Abl}$, and prolong the survival of mice transplanted with bone marrow retrovirally transduced with Bcr-Abl. ${ }^{75-77}$ The combination of imatinib and rapamycin suppressed the growth of imatinibresistant cell lines overexpressing $\mathrm{Bcr}-\mathrm{Abl} .^{74}$ Studies investigating the safety and efficacy of combining imatinib and RAD001 are ongoing in patients with CML.

A novel approach to treating T315I-positive CML is the use of protein phosphatase 2A (PP2A) activators. BCR-ABL1 inhibits PP2A through upregulating the phosphoprotein SET, a PP2A inhibitor. ${ }^{78}$ PP2A activates the phosphatase SHP1, which then catalyzes BCR-ABL1 dephosphorylation, resulting in proteosomal degradation. ${ }^{52}$

FTY720 is a PP2A activator that is structurally similar to sphingosine and is being investigated as an immunomodulator in clinical trials for patients with multiple sclerosis or undergoing renal transplantation. FTY720 suppressed the growth, abolished Bcr-Abl phosphorylation, and induced BcrAbl down-regulation through activating PP2A in imatinib-sensitive and T315I-expressing cell lines and in primary CML cells. ${ }^{79}$ FTY720 also suppressed in vivo wild-type and T315I Bcr-Abl-driven leukemogenesis without causing side effects. ${ }^{79}$

Recent preclinical findings suggest that targeting the Hedgehog signaling pathway or the promyelocytic leukemia protein, which are both critical elements in hematopoietic stem cell maintenance, may represent a promising therapeutic strategy for eradicating BCR-ABL1-positive leukemia stem cells, which are believed to be responsible for relapse after TKI therapy discontinuation in patients with CML. ${ }^{80}$

\section{Identifying More Adequate Second- Generation TKIs for Patients Refractory and Intolerant to Imatinib}

Nilotinib and dasatinib are currently approved as salvage therapy for patients with $\mathrm{Ph}+$ leukemia. Interestingly, dasatinib was initially developed as an immunosuppressant drug and later recognized as a potent bcr-abl inhibitor. Nilotinib was developed as a new-generation imatinib-like molecule with the goal of treating already known mechanisms of resistance, such as Abl kinase domain mutations. Although dasatinib is approved by the FDA for all phases of CML (chronic, accelerated, myeloid, and lymphoid blast crisis), nilotinib is approved for chronic- and accelerated-phase CML.

In the absence of randomized trials to clarify the differences in efficacy and toxicity between the agents, definite recommendations are difficult to make. Nevertheless, in most high-risk patients in chronic-phase CML, some suggestions can be made based on different toxicity profile and emerging data regarding kinase mutations clinical sensitivity. ${ }^{81}$

A review of data from all clinical trials, and considering that the populations studied with both drugs were similar but not equal, suggests that both drugs have comparable response rates. Kinase domain mutations are responsible for $50 \%$ of imatinib-resistant cases; however, the drugs were equally effective independent of the presence of a kinase domain mutation. In the absence of a kinase domain mutation, deciding between the drugs will depend on a review of the potential toxicities, existing comorbid conditions, and patient preferences. $^{82}$

When the presence of a mutation causes clinical resistance, the presence of a T315I mutation must first be assessed (this is found in approximately $10 \%$ of cases). This mutation is not sensitive to any of the currently approved TKIs, and therefore an allogenic stem cell transplant or participation in a clinical trial is advised. In the presence of a P-loop mutation (residues 248-256) and other mutations outside this region (residues 299, 317, and 359), in vitro sensitivity to nilotinib or dasatinib could be a useful guide when choosing between these drugs. For example, dasatinib would be recommended in patients with $\mathrm{Y} 253 \mathrm{H}$ and F359C/V, whereas nilotinib would be a better choice in those with F317V and V299L. ${ }^{83}$ However, most of these mutations represent only a small proportion and most are not associated with a different clinical response to either drug. 
New Agents for CML Treatment

\section{Conclusions}

Imatinib mesylate represents the standard of care for patients with newly diagnosed CML. However, results from the IRIS trial show that an important fraction of patients must discontinue imatinib therapy because of intolerance or resistance. For those patients, alternative forms of therapy are required. Two agents have received approval by regulatory agencies for managing these patients, nilotinib and dasatinib. However, these second-generation TKIs can only rescue approximately half of the patients for whom imatinib therapy fails. Therefore, in light of the growing prevalence of CML, more patients will clearly require further forms of treatment over time. A wide array of promising compounds are being developed in clinical trials. Of particular importance is the development of agents with activity against the T315I mutation, which has proven resistant to imatinib, nilotinib, dasatinib, and bosutinib. Patients with this mutation should be enrolled in clinical trials. These studies will undoubtedly provide novel strategies to better treat patients resistant to conventional TKI therapy or carrying highly resistant BCR-ABL1 mutant isoforms, such as T315I.

\section{References}

1. Buchdunger $\mathrm{E}$, Cioffi CL, Law N, et al. Abl protein-tyrosine kinase inhibitor STI571 inhibits in vitro signal transduction mediated by c-kit and platelet-derived growth factor receptors. J Pharmacol Exp Ther 2000;295:139-145.

2. Druker BJ, Guilhot F, O'Brien SG, et al. Five-year follow-up of patients receiving imatinib for chronic myeloid leukemia. $\mathrm{N}$ Engl J Med 2006;355:2408-2417.

3. Druker BJ, Tamura S, Buchdunger E, et al. Effects of a selective inhibitor of the Abl tyrosine kinase on the growth of Bcr-Abl positive cells. Nat Med 1996;2:561-566.

4. O'Brien SG, Guilhot F, Larson RA, et al. Imatinib compared with interferon and low-dose cytarabine for newly diagnosed chronicphase chronic myeloid leukemia. N Engl J Med 2003;348:9941004.

5. [Package Insert]I. Imatinib Novartis Pharmaceuticals Corporation. 2006.

6. de Lavallade H, Apperley JF, Khorashad JS, et al. Imatinib for newly diagnosed patients with chronic myeloid leukemia: incidence of sustained responses in an intention-to-treat analysis. J Clin Oncol 2008;26:3358-3363.

7. Lucas CM, Wang L, Austin GM, et al. A population study of imatinib in chronic myeloid leukaemia demonstrates lower efficacy than in clinical trials. Leukemia 2008;22:1963-1966.

8. Steegmann JL, Michallet M, Morra E, et al. Imatinib use in chronic phase CML in clinical practice: the UNIC study [abstract]. J Clin Oncol 2008;26(Suppl 1):Abstract 7077.
9. Hochhaus A, La Rosee P. Imatinib therapy in chronic myelogenous leukemia: strategies to avoid and overcome resistance. Leukemia 2004;18:1321-1331.

10. Litzow MR. Imatinib resistance: obstacles and opportunities. Arch Pathol Lab Med 2006;130:669-679.

11. Thomas J, Wang L, Clark RE, Pirmohamed M. Active transport of imatinib into and out of cells: implications for drug resistance. Blood 2004;104:3739-3745.

12. Zong $\mathrm{Y}, \mathrm{Zhou} \mathrm{S}$, Sorrentino BP. Loss of P-glycoprotein expression in hematopoietic stem cells does not improve responses to imatinib in a murine model of chronic myelogenous leukemia. Leukemia 2005;19:1590-1596.

13. Gorre ME, Mohammed M, Ellwood K, et al. Clinical resistance to STI-571 cancer therapy caused by BCR-ABL gene mutation or amplification. Science 2001;293:876-880.

14. Hochhaus A, Kreil S, Corbin AS, et al. Molecular and chromosomal mechanisms of resistance to imatinib (STI571) therapy. Leukemia 2002;16:2190-2196.

15. Krause DS, Van Etten RA. Tyrosine kinases as targets for cancer therapy. N Engl J Med 2005;353:172-187.

16. Lahaye $T$, Riehm B, Berger U, et al. Response and resistance in 300 patients with BCR-ABL-positive leukemias treated with imatinib in a single center: a 4.5-year follow-up. Cancer 2005;103:16591669.

17. Hughes $\mathrm{T}$, Deininger $\mathrm{M}$, Hochhaus $\mathrm{A}$, et al. Monitoring CML patients responding to treatment with tyrosine kinase inhibitors: review and recommendations for harmonizing current methodology for detecting BCR-ABL transcripts and kinase domain mutations and for expressing results. Blood 2006;108:28-37.

18. Deininger M, Buchdunger E, Druker BJ. The development of imatinib as a therapeutic agent for chronic myeloid leukemia. Blood 2005;105:2640-2653.

19. Branford S, Rudzki Z, Walsh S, et al. Detection of BCR-ABL mutations in patients with CML treated with imatinib is virtually always accompanied by clinical resistance, and mutations in the ATP phosphate-binding loop (P-loop) are associated with a poor prognosis. Blood 2003;102:276-283.

20. Jabbour E, Kantarjian HM, Jones D, et al. Characteristics and outcome of chronic myeloid leukemia patients with F317L BCRABL kinase domain mutation after therapy with tyrosine kinase inhibitors. Blood 2008;112:4839-4842.

21. La Rosee P, Corbin AS, Stoffregen EP, et al. Activity of the BcrAbl kinase inhibitor PD180970 against clinically relevant Bcr$\mathrm{Abl}$ isoforms that cause resistance to imatinib mesylate (Gleevec, STI571). Cancer Res 2002;62:7149-7153.

22. Azam M, Latek RR, Daley GQ. Mechanisms of autoinhibition and STI-571/imatinib resistance revealed by mutagenesis of BCR-ABL. Cell 2003;112:831-843.

23. Ban K, Gao Y, Amin HM, et al. BCR-ABL1 mediates up-regulation of Fyn in chronic myelogenous leukemia. Blood 2008;111:29042908.

24. Donato NJ, Wu JY, Stapley J, et al. BCR-ABL independence and LYN kinase overexpression in chronic myelogenous leukemia cells selected for resistance to STI571. Blood 2003;101:690-698.

25. Donato NJ, Wu JY, Stapley J, et al. Imatinib mesylate resistance through BCR-ABL independence in chronic myelogenous leukemia. Cancer Res 2004;64:672-677.

26. Lionberger JM, Wilson MB, Smithgall TE. Transformation of myeloid leukemia cells to cytokine independence by Bcr-Abl is 
suppressed by kinase-defective Hck. J Biol Chem 2000;275:1858118585.

27. Alvarado Y, Kantarjian H, O'Brien S, et al. Significance of suboptimal response to imatinib, as defined by the European LeukemiaNet, in the long-term outcome of patients with early chronic myeloid leukemia in chronic phase. Cancer 2009;115:3709-3718.

28. Kantarjian H, O'Brien S, Shan J, et al. Cytogenetic and molecular responses and outcome in chronic myelogenous leukemia: need for new response definitions? Cancer 2008;112:837-845.

29. Quintas-Cardama A, Kantarjian H, Jones D, et al. Delayed achievement of cytogenetic and molecular response is associated with increased risk of progression among patients with chronic myeloid leukemia in early chronic phase receiving high-dose or standard-dose imatinib therapy. Blood 2009;113:6315-6321.

30. Baccarani M, Saglio G, Goldman J, et al. Evolving concepts in the management of chronic myeloid leukemia: recommendations from an expert panel on behalf of the European LeukemiaNet. Blood 2006;108:1809-1820.

31. Cortes J, Baccarani M, Guilhot F, et al. A phase III, randomized, open-label study of $400 \mathrm{mg}$ versus $800 \mathrm{mg}$ of imatinib mesylate (IM) in patients (pts) with newly diagnosed, previously untreated chronic myeloid leukemia in chronic phase (CML-CP) Using molecular endpoints: 1-year results of TOPS (Tyrosine Kinase Inhibitor Optimization and Selectivity) study [abstract]. Blood 2008;112:Abstract 335.

32. Golemovic M, Verstovsek S, Giles F, et al. AMN107, a novel aminopyrimidine inhibitor of $\mathrm{Bcr}$ - $\mathrm{Abl}$, has in vitro activity against imatinib-resistant chronic myeloid leukemia. Clin Cancer Res 2005;11:4941-4947.

33. Verstovsek S, Golemovic M, Kantarjian H, et al. AMN107, a novel aminopyrimidine inhibitor of p190 Bcr-Abl activation and of in vitro proliferation of Philadelphia-positive acute lymphoblastic leukemia cells. Cancer 2005;104:1230-1236.

34. Weisberg E, Manley PW, Mestan J. AMN107 (nilotinib): a novel and selective inhibitor of BCR-ABL. Br J Cancer 2006;94:17651769.

35. Weisberg E, Manley PW, Breitenstein W, et al. Characterization of AMN107, a selective inhibitor of native and mutant Bcr-Abl. Cancer Cell 2005;7:129-141.

36. O'Hare T, Walters DK, Stoffregen EP, et al. In vitro activity of Bcr-Abl inhibitors AMN107 and BMS-354825 against clinically relevant imatinib-resistant Abl kinase domain mutants. Cancer Res 2005;65:4500-4505.

37. Hochhaus A, Kim DW, Martinelli G, et al. Nilotinib efficacy according to baseline BCR-ABL mutations in patients with imatinib-resistant chronic myeloid leukemia in chronic phase (CML-CP) [abstract]. Blood 2008;112:Abstract 3216.

38. Kantarjian HM, Giles F, Bhalla $\mathrm{KN}$, et al. Nilotinib in chronic myeloid leukemia patients in chronic phase (CMLCP) with Imatinib resistance or intolerance: 2-year follow-up results of a phase 2 study [abstract]. Blood 2008;112:Abstract 3238.

39. le Coutre P, Ottmann OG, Giles F, et al. Nilotinib (formerly AMN107), a highly selective BCR-ABL tyrosine kinase inhibitor, is active in patients with imatinib-resistant or -intolerant acceleratedphase chronic myelogenous leukemia. Blood 2008;111:1834-1839.

40. le Coutre PD, Giles F, Hochhaus A, et al. Nilotinib in chronic myeloid leukemia patients in accelerated phase (CML-AP) with imatinib resistance or intolerance: 2-year follow-up results of a phase 2 study [abstract]. Blood 2008;112:Abstract 3229.
41. Cortes J, O'Brien S, Jones D, et al. Efficacy of nilotinib (formerly AMN107) in patients (pts) with newly diagnosed, previously untreated Philadelphia chromosome (Ph)-positive chronic myelogenous leukemia in early chronic phase (CML-CP) [abstract]. Blood 2008;112:Abstract 446.

42. Lee FY, Wen ML, Bhide R, et al. Dasatinib (BMS-354825) overcomes multiple mechanisms of imatinib resistance in chronic myeloid leukemia (CML) [abstract]. Blood 2005;106:Abstract 1994.

43. Lombardo LJ, Lee FY, Chen P, et al. Discovery of N-(2-chloro6-methyl- phenyl)-2-(6-(4-(2-hydroxyethyl)- piperazin-1-yl)2-methylpyrimidin-4- ylamino)thiazole-5-carboxamide (BMS354825), a dual Src/Abl kinase inhibitor with potent antitumor activity in preclinical assays. J Med Chem 2004;47:6658-6661.

44. PI. Dasatinib Bristol Myers Squibb Company. Sprycel. 2006

45. Schittenhelm MM, Shiraga S, Schroeder A, et al. Dasatinib (BMS354825), a dual SRC/ABL kinase inhibitor, inhibits the kinase activity of wild-type, juxtamembrane, and activation loop mutant KIT isoforms associated with human malignancies. Cancer Res 2006;66:473-481.

46. Talpaz M, Shah NP, Kantarjian H, et al. Dasatinib in imatinibresistant Philadelphia chromosome-positive leukemias. N Engl J Med 2006;354:2531-2541.

47. Tokarski JS, Newitt JA, Chang CY, et al. The structure of dasatinib (BMS-354825) bound to activated ABL kinase domain elucidates its inhibitory activity against imatinib-resistant ABL mutants. Cancer Res 2006;66:5790-5797.

48. Hochhaus A, Baccarani M, Deininger M, et al. Dasatinib induces durable cytogenetic responses in patients with chronic myelogenous leukemia in chronic phase with resistance or intolerance to imatinib. Leukemia 2008;22:1200-1206.

49. Mauro MJ, Baccarani M, Cervantes F, et al. Dasatinib 2-year efficacy in patients with chronic-phase chronic myelogenous leukemia (CML-CP) with resistance or intolerance to imatinib (START-C) [abstract]. J Clin Oncol 2008;26(Suppl 1):Abstract 7009.

50. Stone RM, Kantarjian HM, Baccarani M, et al. Efficacy of dasatinib in patients with chronic-phase chronic myelogenous leukemia with resistance or intolerance to imatinib: 2-year follow-up data from START-C (CA180-013) [abstract]. Blood 2007;110:Abstract 734.

51. Kantarjian H, Pasquini R, Levy V, et al. Dasatinib or high-dose imatinib for chronic-phase chronic myeloid leukemia resistant to imatinib at a dose of 400 to 600 milligrams daily: two-year follow-up of a randomized phase 2 study (START-R). Cancer 2009; 115:4136-4147.

52. Apperley JF, Cortes JE, Kim DW, et al. Dasatinib in the treatment of chronic myeloid leukemia in accelerated phase after imatinib failure: the START A Trial. J Clin Oncol 2009;27:3472-3479.

53. Guilhot F, Apperley JF, Kim DW, et al. Efficacy of Dasatinib in patients with accelerated-phase chronic myelogenous leukemia with resistance or intolerance to imatinib: 2-year follow-up data from START-A (CA180-005) [abstract]. Blood 2007;110:Abstract 470.

54. Gambacorti C, Cortes J, Kim DW, et al. Efficacy and safety of dasatinib in patients with chronic myeloid leukemia in blast phase whose disease is resistant or intolerant to imatinib: 2-year follow-up data from the START program [abstract]. Blood 2007;110:Abstract 472.

55. Stone RM, Kim DW, Kantarjian HM, et al. Dasatinib doseoptimization study in chronic phase chronic myeloid leukemia (CML-CP): three-year follow-up with dasatinib $100 \mathrm{mg}$ once daily 
New Agents for CML Treatment

and landmark analysis of cytogenetic response and progression-free survival (PFS) [abstract]. J Clin Oncol 2009;27(Suppl 1):Abstract 7007.

56. Cortes J, O'Brien S, Borthakur G, et al. Efficacy of dasatinib in patients (pts) with previously untreated chronic myelogenous leukemia (CML) in early chronic phase (CML-CP) [abstract]. Blood 2008;112:Abstract 182.

57. Cortes J, Kantarjian HM, Kim DW, et al. Efficacy and safety of bosutinib (SKI-606) in patients with chronic phase (CP) $\mathrm{Ph}+$ chronic myelogenous leukemia (CML) with resistance or intolerance to imatinib [abstract]. Blood 2008;112:Abstract 1098.

58. Passerini CG, Pogliani EM, Baccarani M, et al. Bosutinib (SKI606) demonstrates clinical activity and is well tolerated in patients with AP and BP CML and Ph+ ALL [abstract]. Blood 2008;112:Abstract 1101.

59. Naito H, Kimura $S$, Nakaya $Y$, et al. In vivo antiproliferative effect of NS-187, a dual Bcr-Abl/Lyn tyrosine kinase inhibitor, on leukemic cells harbouring Abl kinase domain mutations. Leuk Res 2006;30:1443-1446.

60. Yokota A, Kimura S, Masuda S, et al. INNO-406, a novel BCRABL/Lyn dual tyrosine kinase inhibitor, suppresses the growth of $\mathrm{Ph}+$ leukemia cells in the central nervous system, and cyclosporine A augments its in vivo activity. Blood 2007;109:306-314.

61. Kantarjian HM, Cortes J, le Coutre P, et al. A phase I study of INNO-406 in patients with advanced Philadelphia $(\mathrm{Ph}+)$ chromosome-positive leukemias who are resistant or intolerant to imatinib and second generation tyrosine kinase inhibitors [abstract]. Blood 2007;110:Abstract 469.

62. Pinilla-Ibarz J, Kantarjian HM, Cortes JE, et al. A phase I study of INNO-406 in patients with advanced Philadelphia chromosomepositive $(\mathrm{Ph}+)$ leukemias who are resistant or intolerant to imatinib and may have also failed second-generation tyrosine kinase inhibitors [abstract]. J Clin Oncol 2008;26(Suppl 1):Abstract 7018.

63. Nigg EA. Mitotic kinases as regulators of cell division and its checkpoints. Nat Rev Mol Cell Biol 2001;2:21-32.

64. Giles FJ, Cortes J, Jones D, et al. MK-0457, a novel kinase inhibitor, is active in patients with chronic myeloid leukemia or acute lymphocytic leukemia with the T315I BCR-ABL mutation. Blood 2007;109:500-502.

65. Shah NP, Kasap C, Paquette R, et al. Targeting drug-resistant CML and $\mathrm{Ph}+$-ALL with the spectrum selective protein kinase inhibitor XL228 [abstract]. Blood 2007;110:Abstract 474.

66. Cortes J, Paquette R, Talpaz M, et al. Preliminary clinical activity in a phase I trial of the BCR-ABL/IGF-1R/Aurora kinase inhibitor XL228 in patients with $\mathrm{Ph}++$ leukemias with either failure to multiple TKI therapies or with T315I mutation [abstract]. Blood 2008;112:Abstract 3232.

67. Paquette RL, Shah NP, Sawyers CL, et al. PHA-739358, an Aurora kinase inhibitor, induces clinical responses in chronic myeloid leukemia harboring T315I mutations of BCR-ABL [abstract]. Blood 2007;110:Abstract 1030.

68. Van Etten RA, Chan WW, Zaleskas VM, et al. Switch pocket inhibitors of the ABL tyrosine kinase: distinct kinome inhibition profiles and in vivo efficacy in mouse models of CML and B-lymphoblastic leukemia induced by BCR-ABL T315I [abstract]. Blood 2008;112:Abstract 576.

69. Cortes J, Khoury, HJ, Corm, S, et al. Subcutaneous omacetaxine mepesuccinate in imatinib-resistant chronic myeloid leukemia (CML) patients (Pts) with the T315I mutation: Data from an ongoing phase II/III trial [abstract]. J Clin Oncol 2009;27(Suppl 1):Abstract 7008.

70. Nimmanapalli R, Fuino L, Stobaugh C, et al. Cotreatment with the histone deacetylase inhibitor suberoylanilide hydroxamic acid (SAHA) enhances imatinib-induced apoptosis of Bcr-Abl-positive human acute leukemia cells. Blood 2003;101:3236-3239.

71. Bali P, Pranpat $M$, Bradner J, et al. Inhibition of histone deacetylase 6 acetylates and disrupts the chaperone function of heat shock protein 90: a novel basis for antileukemia activity of histone deacetylase inhibitors. J Biol Chem 2005;280:26729-26734.

72. Fiskus W, Pranpat M, Bali P, et al. Combined effects of novel tyrosine kinase inhibitor AMN107 and histone deacetylase inhibitor LBH589 against Bcr-Abl-expressing human leukemia cells. Blood 2006;108:645-652.

73. Fiskus W, Pranpat M, Balasis M, et al. Cotreatment with vorinostat (suberoylanilide hydroxamic acid) enhances activity of dasatinib (BMS-354825) against imatinib mesylate-sensitive or imatinib mesylate-resistant chronic myelogenous leukemia cells. Clin Cancer Res 2006;12:5869-5878.

74. Ly C, Arechiga AF, Melo JV, et al. Bcr-Abl kinase modulates the translation regulators ribosomal protein S6 and 4E-BP1 in chronic myelogenous leukemia cells via the mammalian target of rapamycin. Cancer Res 2003;63:5716-5722.

75. Dengler J, von Bubnoff N, Decker T, et al. Combination of imatinib with rapamycin or RAD001 acts synergistically only in Bcr-Ablpositive cells with moderate resistance to imatinib. Leukemia 2005; 19:1835-1838.

76. Mayerhofer M, Aichberger KJ, Florian S, et al. Identification of $\mathrm{mTOR}$ as a novel bifunctional target in chronic myeloid leukemia: dissection of growth-inhibitory and VEGF-suppressive effects of rapamycin in leukemic cells. Faseb J 2005;19:960-962.

77. Mohi MG, Boulton C, Gu TL, et al. Combination of rapamycin and protein tyrosine kinase (PTK) inhibitors for the treatment of leukemias caused by oncogenic PTKs. Proc Natl Acad Sci U S A 2004;101:3130-3135.

78. Neviani P, Santhanam R, Trotta R, et al. The tumor suppressor PP2A is functionally inactivated in blast crisis CML through the inhibitory activity of the BCR/ABL-regulated SET protein. Cancer Cell 2005;8:355-368.

79. Neviani P, Santhanam R, Oaks JJ, et al. FTY720, a new alternative for treating blast crisis chronic myelogenous leukemia and Philadelphia chromosome-positive acute lymphocytic leukemia. J Clin Invest 2007;117:2408-2421.

80. Dierks C, Beigi R, Guo GR, et al. Expansion of Bcr-Abl-positive leukemic stem cells is dependent on Hedgehog pathway activation. Cancer Cell 2008;14:238-249.

81. Jabbour E, Jones D, Kantarjian HM, et al. Long-term outcome of patients with chronic myeloid leukemia treated with secondgeneration tyrosine kinase inhibitors after imatinib failure is predicted by the in vitro sensitivity of BCR-ABL kinase domain mutations. Blood 2009;114:2037-2043.

82. Mauro MJ. Appropriate sequencing of tyrosine kinase inhibitors in chronic myelogenous leukemia: when to change? A perspective in 2009. Curr Opin Hematol 2009;16:135-139.

83. Jabbour E, Soverini S. Understanding the role of mutations in therapeutic decision making for chronic myeloid leukemia. Semin Hematol 2009;46:S22-26.

84. Gambacorti-Passerini C, Pogliani E, Baccarani M, et al. Bosutinib (SKI-606) demonstrates clinical activity and is well tolerated in patients with AP and BP CML and Ph+ ALL [abstract]. Blood 2008;112:Abstract 1101. 